\title{
Literatura e cultura da diversidade no modernismo brasileiro
}

\author{
Litterature et culture de la diversite dans le modernisme bresilien \\ Sebastião Marques CARDOSO* \\ Universidade do Estado do Rio Grande do Norte (UERN)
}

\begin{abstract}
RESUMO: No contexto da literatura brasileira da primeira metade do século XX, vamos tratar, inicialmente, de dois autores cuja imaginação esteve empenhada em reelaborar o mito da identidade nacional: Paulo Prado [1869-1943] e Oswald de Andrade [1890-1954]. Ambos procuraram dar uma resposta ao problema que, no âmbito da cultura da época, surgia como enigma, mas com estratégias distintas, como veremos, apesar de convergências em alguns pontos. Em seguida, iremos traçar um paralelo entre a noção de "crioulização" de Édouard Glissant, passando pelas considerações teóricas de Raphaël Confiant, e o construto antropofágico e literário de Oswald de Andrade. Por fim, deduziremos que o escritor paulista elabora uma noção de mestiçagem mais restritiva e datada na concepção crítica, ainda que mais avançada em relação a Paulo Prado. Será no texto literário que Oswald, contudo, deixará uma marca de mestiçagem, tanto na forma como no conteúdo, mais aberta e atual.
\end{abstract}

PALAVRAS-CHAVE: Modernismo Brasileiro, Identidade Nacional e Cultura Literária, Oswald de Andrade.

RÉSUME: Dans le contexte de la littérature brésilienne au XXe siècle, nous allons étudier, premièrement, deux auteurs dont l'imagination était engagée en recréer le mythe de l'identité nationale: Paulo Prado [1869-1943] et Oswald de Andrade [1890-1954]. Ces deux auteurs ont cherché donner une réponse au problème qui se pose dans le domaine de la culture de la période comme énigme, mais chaqu'un avec une manière différente, comme nous pouvons voir en suite, malgré certains points en commun. Deuxièmement, nous allons faire une comparaison entre l'idée de "créolisation" de Édouard Glissant, en passant sur les points théoriques de Raphaël Confiant, et la notion anthropophagique et littéraire de Oswald de Andrade. Finalement, nous allons faire conclure que l'écrivain de São Paulo donne une notion de métissage moins élaborée, fixée dans le temps, au niveau de la théorie critique, bien que plus élevée, encore, par rapport à Paulo Prado. Ça va être dans le texte littéraire que Oswald, pourtant, va laisser une trace de métissage tant sur la forme comme sur le contenu, plus ouverte et actuel.

MOTS-CLES: Modernisme Brésilien, Identité Nationale et Culture Littéraire, Oswald de Andrade.

\section{Introdução}

“[...] é impressionante que, em pleno século 21, o Brasil não tenha conseguido formar uma sociedade múltipla, onde entram negros, mulatos, índios e brancos". (LEAL, 2011).

\footnotetext{
* Pós-doutorando em Literaturas Africanas de Língua Portuguesa pelo Departamento de Letras Clássicas e Vernáculas da USP, doutorado em Teoria e História Literária (UNICAMP), docente do Departamento de Letras Estrangeiras e do Programa de Pós-Graduação em Letras da Universidade do Estado do Rio Grande do Norte (UERN), campus de Pau dos Ferros- RN. Email: sebastiaomarques@uol.com.br.
} 
Quando passamos os olhos sobre a recepção do pensamento e da literatura de Oswald de Andrade, desde suas primeiras manifestações, quando escreve, por exemplo, uma peça em francês em parceria com Guilherme de Almeida, em 1916, ao mesmo tempo em que inicia Memórias sentimentais de João Miramar, o escritor paulista apresenta uma dimensão criativa multifacetada e perturbadora que, como disse certa vez Antonio Candido (1995), surge como desafio à crítica e, não com pouca freqüência, faz rasteira em muito crítico de primeira hora, no afã de sistematizá-lo em poucas linhas. Sabemos do risco que corremos, mas entendemos que a crítica é o exercício do livre arbítrio, é, pois, mais uma tentativa do que uma certeza em ver, a partir da realidade do próprio tempo, certas conexões ainda não plasmadas ou não esmiuçadas por outras vozes. A crítica postula, enfim, projetar novas identificações com a realidade que nos cerca.

Cremos que o conhecimento acerca do pensamento e da obra literária de Oswald não está fora de linha, restrito, tão somente, ao quadro do modernismo literário brasileiro. Quando buscamos uma interface com as linhas de raciocínio da atualidade, que discutem questões ligadas à cultura, à identidade e à progressão do capitalismo, Oswald surge, novamente, como um notável interlocutor, descontados os anos corridos e o uso (ideológico) de terminologias já abandonadas. Então, trazemos, como provocação, de volta Oswald de Andrade. Décio Pignatari (1971) afirma que toda vez que o cadáver do escritor vem à tona assusta muita gente. Assusta porque o conhecimento que tiramos dele pode, de outra maneira, abalar nossa percepção tácita ou conservadora do mundo. Abala, enfim, nossa tranqüilidade e nos faz mergulhar no terreno pantanoso da cultura.

No mesmo período em que Oswald de Andrade exercia sua força crítica através sobretudo do "Manifesto da poesia pau-brasil" (1924) e do "Manifesto antropofágico" (1928), Mário de Andrade dava também sua contribuição pioneira com "Prefácio interessantíssimo" (1920) e com "A escrava que não era Isaura" (texto composto em 1922, mas publicado em 1925). Esses engajamentos estéticos, culturais e políticos através dos manifestos tinham, como pano de fundo, a busca de um "caráter nacional" mais adequado, como substrato da cultura e da antropologia. Jorge Schwartz (1995), ao fazer um levantamento dos movimentos de vanguarda na América Latina, conclui que, no continente, nenhum outro movimento atingiu a diversidade e a amplitude da reflexão crítica propostas pelos modernistas brasileiros na década de 20.

Embora, no contexto da América Latina, como disse o argentino Jorge Schwartz (1995), o modernismo tivesse sido mais dinâmico, sua acomodação na história literária nacional, sobretudo da figura de Oswald de Andrade, cristalizou uma leitura arrefecida sobre suas principais preocupações, pois sua incorporação à tradição, agora na visão do crítico brasileiro Roberto Schwarz (1987), teria subtraído grande parte de sua força contestatória e utópica. O crítico nos alerta para não tomarmos tout court o modernismo e suas vanguardas como aspirações já executadas e datadas, ou seja, como realizações concretas de nossa literatura. Isso nos levaria supor que as aspirações libertárias teriam sido alcançadas e que, por isso, não precisaríamos mais hoje relembrá-las.

\section{Identidade nacional e mistos culturais: Oswald (re)lendo Paulo Prado}

\footnotetext{
"Só a Antropofagia nos une. Socialmente. Economicamente. Filosoficamente". Oswald de Andrade- Manifesto Antropófago, 1928.

"Les Antilles ont été, en effet, le lieu d'une première globalisation, entre le XVIIe et le XIXe siècles, et sont sans doute la partie du monde la mieux placée pour en percevoir les enjeux c'est-à-dire à la fois les dangers et les formidables avancées". [As Antilhas foram, com efeito, o lugar de uma primeira globalização, entre os séculos XVII e XIX, e sem dúvida a parte do mundo
} 
melhor situada para perceber os desafios, ou seja, por sua vez os perigos e os formidáveis avanços]. (CONFIANT, 2005).

Contemporâneo a Oswald, Paulo Prado tratou de, para dizer a identidade nacional, traçar a diacronia de eventos da colonização por meio do ensaio crítico. A historiografia do imaginário do passado colonial, como o autor habilmente demonstrou em Retrato do Brasil [1928, primeira edição], o conduzirá a uma formulação amarga acerca do brasileiro com base em apontamentos da história, seguindo a orientação metodológica de Capistrano de Abreu, historiador cearense de grande repercussão no período. Vamos ouvir falar o próprio Paulo Prado (1997, p. 141-142):

\footnotetext{
No Brasil a tristeza sucedeu à intensa vida sexual do colono, desviada para as perversões eróticas, e de um fundo acentuadamente atávico. Por sua vez a cobiça é uma entidade mórbida, uma doença do espírito, com seus sintomas, suas causas e evolução. Pode absorver toda a energia psíquica, sem remédios para o seu desenvolvimento, sem cura para os seus males. Entre nós, por séculos, foi paixão insatisfeita, convertida em idéia fixa pela própria decepção que a seguia. Absorveu toda a atividade dinâmica do colono aventureiro, sem que nunca lhe desse a saciedade da riqueza ou a simples tranqüilidade da meta atingida. No anseio da procura afanosa, na desilusão do ouro, esse sentimento é também melancólico, pela inutilidade do esforço e pelo ressaibo da desilusão.
}

Para Prado, o efeito da colonização gerou, dentre outras coisas, um descendente tropical melancólico, vítima da empresa colonizadora, dos povos autóctones e da mistura de raças. Para ele, para vencer essa apatia de nossa formação moral, psicológica e étnica, só seria possível pelo viés da guerra ou da revolução. As condicionantes históricas poderiam ser, então, reencetadas no plano da política, como forma de esconjurar o passado para criar novas condições para uma imagem positiva da identidade nacional. Uma nova narrativa sobre o Brasil poderia, então, ser contada (WHITE, 2001).

A propósito da publicação de Retrato do Brasil, Oswald de Andrade, apesar de ver no livro certa congenialidade com Macunaíma, ficção de Mário de Andrade publicada no mesmo ano, censura-o não na disposição do conteúdo, no estilo adotado, mas na avaliação que faz daquilo que brilhantemente descreve:

Os quadros da vida de luxo de senhores, escravos, negros e índios, os séquitos, as procissões, os corpos nus sob a cambraia caseira, tudo isso bem documentado, bem pintado, bem vivido, é um hino que fura qualquer invólucro de falso pessimismo e a gente sente em cada página assim colorida o arrimo histórico de Macunaíma. (ANDRADE, 1997, p. 232).

Para Oswald, Paulo Prado foi, no juízo, doutrinário, e repetitivo, na avaliação do passado da colonização. Prado, na visão de Oswald, traiu a própria coerência da vida intelectual compartilhada e professada no tempo modernista, atribuindo a essa mudança de postura, a fidelidade do autor ao pensamento de Capistrano de Abreu. Mas, em resenha de José Lins do Rego (1997), de 1943, essa presença do historiador cearense foi positiva, pois deu ao talento artístico do autor o rigor da análise científica.

A obra de Paulo Prado, de acordo com sua recepção, se inscreve numa fissura entre o peso da historiografia da imaginação e o apelo da imaginação historiográfica. Quando o pêndulo se volta à seriedade da documentação, a narrativa do Brasil, elaborada por Paulo Prado, apresenta-se sombria, lastimável e triste. Quando o pêndulo se volta à imaginação de uma nova historiografia, o autor se esquiva do fardo do enredo documental que ele 
mesmo o reacendeu, e, então, se lança num novo enredo, desejando agora uma história de ruptura, por meio de tensões sociais mais graves.

Em Oswald de Andrade, o conflito posto por Paulo Prado (1997) foi uma preocupação constante tanto na vida artística quanto na vida intelectual. A escrita de uma nova historiografia, ou seja, de uma nova imaginação sobre a história, para escapar do estigma da interpretação alienígena assimilada e absolutamente mimética, e para fundar, ao mesmo tempo, uma visão atualizada e tropical sobre a identidade nacional, moveu-o na luta política e no campo da arte. Na poesia, Oswald (2000) surpreendeu, recontando a história do Brasil, deslocando o continente em partes, ilhas que percebem choques e contribuições estrangeiras, numa visada positiva e criativa para a sociedade brasileira. Para Schwarz (1987), Oswald fez uma equação otimista do Brasil, transformando temas comumente associados ao atraso e desgraça nacionais numa linguagem poética e sábia que não rejeita as vantagens do progresso, no contexto da nova ordem burguesa, desrecalcada e fraterna.

Mas como, efetivamente, Oswald consegue converter a história "negativa" da colonização numa imagem "positiva" para a identidade do brasileiro sem, é claro, endossar ou esquecer os desmandos cometidos em todo processo? A solução oswaldiana foi a antropofagia cultural. Para Nunes (1995), três aspectos, num só tempo, sintetizam a idéia de devoração oswaldiana: "metáfora", "diagnóstico" e "terapêutica". Como "metáfora orgânica", trata de uma cena guerreira de imolação pelos tupis do inimigo preso em combate, que traz tudo aquilo que poderíamos repudiar, assimilar e superar para a conquista definitiva da autonomia intelectual. Como "diagnóstico". Trata de informar sobre o caráter traumático da sociedade brasileira, em face da repressão colonizadora. Veja-se, por exemplo, que o próprio rito de antropofagia foi reprimido pelos jesuítas. E como "terapêutica": a própria reação (manifestação) a essa repressão histórica de forma igualmente violenta e sistemática, articulando, também, todas as artes nesse propósito.

No domínio da "terapêutica", encontramos a literatura de Oswald, bem como a própria proposta dos modernistas da hora. Em Serafim Ponte Grande (1990), livro concluído em 28, mesmo ano da publicação de Retrato do Brasil (1997), o escritor paulista encerra o livro com uma violência simbólica descomunal, como forma de reação a toda violência sofrida e assimilada pelo passado brutal da colonização, o que teria culminado, na análise de Paulo Prado, na formação de um povo sem empatia, moralmente sensível e triste.

No livro de Oswald, depois de "Errata", vêm "Os antropófagos". Esse último texto do romance surge como o verdadeiro fim de Serafim (ou recomeço de tudo e do livro): "Passaram a fugir o contágio policiado dos portos, pois que eram a humanidade liberada". (ANDRADE,1990, p. 97). Haroldo de Campos define essa unidade como "um pandemônio com ressaibos de farsa medieval, de missa negra e ritual fálico". (CAMPOS, 1990, p. 19). Mas, resumidamente, essa mesma unidade do livro aparece melhor, ainda nas palavras de Haroldo, como "a utopia da viagem permanente e a reeducação, à maneira de Sade, da virtude pelo vício, num exercício de liberdade total como radical negativadade". (CAMPOS, 1990, p. 19). Antonio Candido (apud CAMPOS, 1990, p. 19) vê, ainda sobre essa passagem, a crosta da formação burguesa e conformista da sociedade brasileira, voltada à utopia da viagem, permanente e redentora, da "plenitude através da mobilidade".

Ora, o que podemos depreender desses autores, cortados pela mesma época, preocupados com as mesmas questões? Paulo Prado, na sua historiografia, imaginou um país de brasileiros através de um discurso metonímico, ou seja, viu a figuração da "brasilidade" como resultado da "luxúria" e da "cobiça", misturadas à variedade de raças 
não européias. A posição de Paulo Prado reserva, assim, um mal estar com relação à identidade nacional, como experiência mal sucedida.

Por outro lado, Oswald de Andrade melhor se caracteriza pela metáfora e pela ironia. O brasileiro é, agora, o "europeu barbarizado", ou seja, aquele que responde, na mesma medida, à violência sofrida pelos ancestrais locais do passado. Oswald quer, com isso, equalizar a relação centro-periferia. É pelo raio da periferia, agora, que exercerá influência sobre o centro, reeducando-o à sua maneira. Trata-se, portanto, de uma imagem irônica e intimidadora, do pagamento em juros pela violência cometida. Com o romance Serafim, temos uma elite brasileira sem culpa, anárquica, mas globalizada. A literatura oswaldiana aparece, então, como espaço de contato entre culturas, figurando suas antinomias e perigos, mas, também, reservando a si mesma um horizonte de experimentação e de transformação. Ou seja, ela surge como aposta contra a opressão e contra a resignação do oprimido.

Nesse sentido, Paulo Prado e Oswald de Andrade investiram sua imaginação na elucidação de uma identidade nacional que respondesse aos anseios da época. Embora com perspectivas diferentes, ambos representaram a cultura de elite identificada com as idéias mais progressistas, mas ainda incerta sobre sua própria representatividade no meio social. Com eles, enfim, nossa historiografia foi reescrita, e, com isso, a cultura literária (de elite) também foi repensada, redirecionada e resignificada. Com isso, história e literatura foram solidárias na inscrição de uma narrativa nacional, restritiva em Paulo Prado, mas extensiva em Oswald de Andrade.

\title{
2 Mestiçagem cultural no modernismo brasileiro
}

\begin{abstract}
“A língua sem arcaísmos. Sem erudição. Natural e neológica. A contribuição milionária de todos os erros". Oswald de Andrade- Manifesto da poesia PauBrasil, 1924.

"Entrer dans l'imaginaire $d u$ non idéologique, du non impératif, du non oppressif et du non impérialiste, c'est cela la Créolisation: je peux devenir toi et tu peux devenir moi sans que je me perde, sans que je me dilue et sans que je me trahisse". ["Entrar no imaginário do não ideológico, do não imperativo, do não opressivo e do não imperialista, é isso a Crioulização: eu posso tornar-me você e você pode se tornar eu sem que eu me perca, sem que eu me dilua e sem que eu me traia"]. (GLISSANT,1999).
\end{abstract}

Ora, levando em consideração o trabalho de abertura de Jorge Schwartz, no esforço de ler o modernismo brasileiro numa dimensão mais ampla, bem como as observações de Roberto Schwarz, vamos, a partir de agora, traçar uma linha transversal que procura unir parte da preocupação estético-ideológica de Oswald de Andrade a um movimento de reivindicação cultural cuja origem aponta para questões culturais igualmente complexas, com desdobramentos críticos de grande repercussão na contemporaneidade. Vamos, enfim, traçar um paradigma que aproxima o horizonte imaginado de Oswald de Andrade às principais bandeiras de Édouard Glissant (1981), martiniquenho nascido em 1928, no mesmo ano da fundação da "Revista de Antropofagia".

As diferenças territoriais são enormes quando buscamos interlocuções entre um autor brasileiro e um martiniquenho. O Brasil é um país continental e Martinica é um Departamento francês, situado no arquipélago das Antilhas. Trata-se de uma ilha a $450 \mathrm{~km}$ aproximadamente de distância da América do Sul. Seu nome decorre da passagem de Cristóvão Colombo em 1502. Guardadas as diferenças, a história os une no que diz respeito à colonização européia, à diáspora africana e às reivindicações de autoctonia. Nesse aspecto, as fronteiras podem ser esgarçadas, ou até diluídas, pois o que nos assalta é 
a resistência dos povos diante de um imaginário europeu (local) que se universaliza pela imposição (global).

Em Martinica, a noção de "crioulidade", que se introduz em fins dos anos 80 do século XX, procura se estabelecer depois do percurso de ideologias de afirmação identitária que tinham, em comum, um fundamento na raça ou numa relação de classe. Assim, antes da "crioulidade", defendida por Raphaël Confiant (2005), a ilha se deparou inicialmente com a "Branquitude", que perdurou por dois séculos e meio, com a "Negritude", entre os anos 30 e 60 do século XX, e com a "Hinduinidade", entre os anos 70 e 90 . No entanto, a mestiçagem, hoje, corresponde a $90 \%$ da população martiniquenha, não se encaixando satisfatoriamente em nenhuma das reivindicações anteriores. Para Confiant (2005), essa realidade, ou seja, esse povo constituído basicamente de mestiços, necessita, então, reconhecer essa nova autoctonia, ao tomar consciência de sua formação identitária. Essa nova formação permite sair, por exemplo, de um pensamento raciológico ou de identidade única, fechada.

No Brasil, a "Branquitude" dominou todo o cenário cultural. O que podemos notar, na sua trajetória, é a ocorrência de manchas culturais que tentaram contestar essa hegemonia, como, em certa medida, ocorreu no Romantismo e, sobretudo, no Modernismo. Entendemos "Branquitude" como o aparato do modo de vida europeu (político, religioso, estético, econômico e social), em contraste com outras formas de vida. No Romantismo, tivemos a primeira tentativa de repercussão da valorização do homem local, na construção simbólica e valorativa do índio.

$\mathrm{Na}$ verdade, o que podemos perceber na literatura de Alencar, por exemplo, é a representação de um índio focalizado por um imaginário alheio, que o transforma em gente dócil, educada e cristã, bem distante de uma expressão antropológica afirmativa do imaginário indigenista. O discurso "indigenista" foi conduzido por letrados- o que era uma minoria branca-, mais interessados em marcar, através da figura estilizada do índio, sua diferença em relação ao homem branco da metrópole. Foi, mesmo assim, o indigenismo nacional uma afirmação identitária posta por um grupo social definido, que aqui vivia, e que não mais queria continuar ligado visceralmente ao contexto europeu. No Romantismo brasileiro, o diverso, o índio, foi tragado pela raiz cultural do colonizador.

Mais adiante, o modernismo foi, em certa medida, um desdobramento da expressão cultural da elite nacional, mas agora reivindicada por grupos emergentes e de forças antagônicas, que propunham projetos em que a questão da autoctonia novamente é posta. A figura do índio ressurge, mas agora não mais "civilizado" como no Romantismo, mas como elemento de vanguarda européia, abusado, indolente, mitificado por aquilo agora que se choca com o comportamento ocidental, mais como discurso crítico e rebarbativo oriundo mesmo do seio da cultura européia. Com o modernismo, a "Branquitude" novamente se atualiza às custas do índio forjado. No processo brutal de colonização, nossos verdadeiros índios não tiveram visibilidade, mas, como suspeitamos, resistiram à imposição do imaginário. Da mesma forma, podemos dizer dos negros, vindos a posteriori a constituir mais um grupo étnico de presença no país.

Ora, mesmo tendo ultrapassado o "senso comum" da literatura (COMPAGNON, 2006), os usos de uma imagem do índio como sujeito dócil ou estilizado no Romantismo, bem como uma figuração à Montagne do bárbaro e que também encerra uma comunidade em oposição ao Patriarcado (como ocorre no Modernismo pelo viés de Oswald de Andrade), não constituem um dado antropológico válido para autocertificar a(s) identidade(s) em curso da nação. As disputas e o convívio entre os vários grupos étnicos existentes indicam mais uma "mistura" entre si, mas que, ainda, não se destacou discursivamente através de um pensamento próprio, fazendo "visível" a sua própria 
consciência. Com a simbólica da antropofagia, Oswald de Andrade pensou um conversor que, ao tomar a informação nova, alheia e imposta, gerava um produto que se acomodava numa ordem já existente (miticamente), no Matriarcado. Como na "Branquitude", o Matriarcado tende à totalização, ou seja, à universalização de seus valores.

Se, por um lado, Oswald não se desvincula de fato do modus operandi da cultura ocidental, por outro lado, sua literatura- desteorizada e descritiva- aponta para uma perspectiva estético-antropológica sem precedentes, como podemos atestar em alguns de seus poemas, por nós numerados, retirados de Pau-Brasil (ANDRADE, 2000, p. 86, 87, 88 e 120):

\section{(1) Caso}

A mulatinha morreu

E apareceu

Berrando no moinho

Socando pilão

\section{(2) Medo da Senhora}

A escrava pegou a filhinha nascida

Nas costas

E se atirou no Paraíba

Para que a criança não fosse judiada

\section{(3) Senhor Feudal}

Se Pedro Segundo

Vier aqui

Com história

Eu boto ele na cadeia

\section{(4) Pronominais}

Dê-me um cigarro

Diz a gramática

Do professor e do aluno

E do mulato sabido

Mas o bom negro e o bom branco

Da Nação Brasileira

Dizem todos os dias

Deixa disso camarada

Me dá um cigarro

Nos poemas, notamos que o oral, coloquialismo, e o escrito- língua oficial/padrãosão postos em "relação" por meio da "mestiçagem" (GLISSANT, 1981). No poema 1, "Caso", há uma referência explícita à mestiçagem, através da palavra "mulatinha" (oralidade), nota-se ainda uma visada ideológica sobre ela através do uso do diminutivo. Por outro lado, sua aparição no pilão depois de morta, agressiva aos olhos do Senhor, surge como um substrato de resistência da cultura africana, fincado no imaginário do opressor, do qual não pode mais se desprender. O poema revela também a situação de classe da sociedade brasileira. 
No poema 2, "Medo da Senhora", a narrativa de resistência dos sujeitos "invisíveis" da sociedade é retomada através dos versos. Trata-se de uma cena da colonização vista, agora, sob o espectro do colonizado. Com esse poema, Oswald consegue, através de uma forma poética modernista, captar o imaginário do "diverso". O próprio poema, nesse sentido, se apresenta como criação "híbrida" (CANCLINI, 1998), aliando a forma poética à expressão do imaginário coletivo. Contrariamente, temos o poema 3, "Senhor Feudal". Nesse poema, a voz patriarcal local, já amestiçada, se manifesta. Trata-se de um poder local que sublima a contribuição imanente do Outro, pois absorve seu extrato expressivo, que, através dele, se pronuncia. A "voz" do Outro é dita sob a perspectiva da autoridade senhorial.

No poema 4, "Pronominais", Oswald, através da variação lingüística selecionada, sintetiza muito bem a situação da língua em uso no Brasil e informa os grupos discursivos que a praticam. O gramático, representante máximo da "Branquitude", impõe a norma (alheia). O "mulato sabido" tira proveito. Mas são o negro- "bom negro"- e o branco"bom branco", já mestiços culturalmente, que adotam sem preconceitos a variação como nova norma no grupo dos "bons" brasileiros.

Note-se que, tanto no poema 1, quando nesse último poema que acabamos de ver, o "mulato" aparece de forma pejorativa. Paradoxalmente, Oswald faz um hino à mestiçagem cultural, mas, como não se desprendeu por completo do paradigma da raça, tem dificuldade em afirmar, estritamente, as identidades miscigenadas (GRUZINSKI, 2001). Com Oswald, vislumbra-se uma nova autoctonia cultural, que é a da mestiçagem, mas ele não percebe que atrelado a esse preceito, deve-se promover também a autoctonia do próprio povo mestiço. Como na "crioulidade", o discurso da mestiçagem não pode se guiar pelo critério de classe e nem de raça.

\section{Conclusão}

$\mathrm{Na}$ produção de Oswald, interessa-nos, sobretudo, as fraturas estético-discursivas ocorridas por conta do caráter "mestiço" e "híbrido" que elas apontam. Essas fissuras, longe de sublinhar uma tentativa frustrada de invenção, indicam mais um arranjo complexo (artimanha de "mulato sabido?") que procura harmonizar cruzamentos de procedimentos estéticos de várias origens, muitas vezes contraditórios. Em trabalho anterior, por exemplo, procuramos sondar como a consciência de Oswald de Andrade se debate para materializar uma forma romanesca em que a técnica empregada (cinematográfica) se choca com uma visão ainda balzaquiana de construção de personagens num contexto literário periférico e atrasado (CARDOSO, 2010). É nessa colcha de retalhos- que poderíamos chamar muito bem de intertextualidade ou mistos discursivos- que a posição do autor se inscreve e se faz visível.

\section{REFERÊNCIAS}

ANDRADE, O. de. Pau-brasil. Fixação de textos e notas de Haroldo de Campos. 5. ed. São Paulo: Globo, 2000.

ANDRADE, O. de. Retoques ao Retrato do Brasil. In: PRADO, P. Retrato do Brasil. Organização Carlos Augusto Calil. São Paulo: Companhia das Letras, 1997.

ANDRADE, O. de. Serafim Ponte Grande. São Paulo: Globo: Secretaria de Estado de Cultura, 1990. 
ANDRADE, O. de. A utopia antropofágica. 2. ed. São Paulo: Globo, 1995.

CAMPOS, H. de. Serafim: um grande não livro. In: ANDRADE, O. de. Serafim Ponte Grande. São Paulo: Globo: Secretaria de Estado da Cultura, 1990.

CANCLINI, N. G. Culturas híbrida: estratégias para entrar e sair da modernidade. Tradução Ana Regina Lessa; Helosísa Pezza Cintrão. 2. ed. São Paulo: EdUsp, 1998.

CANDIDO, A. Estouro e libertação. In: Vários escritos. 3. ed. São Paulo: Duas Cidades, 1995.

CARDOSO, S. Oswald de Andrade: anti-heroísmo, literatura e crítica. Curitiba: Editora CRV, 2010.

COMPAGNON, A. O demônio da teoria. Literatura e senso comum. Tradução Cleonice P. B. Mourão; Consuelo Fortes Santiago. Belo Horizonte: Editora UFMG, 2006.

CONFIANT, R. La créolité contre l'enfermement identitaire. Revista Multitudes, v. 3, n. $22,2005$.

GLISSANT, E. Un peuple invisible pour sauver le monde réel. Entretien d'Héric Libong et Boniface Mongo-Mboussa. Entrevista concedida à Revista Africultures em 1999. Disponível em http://www.africultures.com/php/index.php?nav=article\&no=1071. Acesso em 02 de dez 2011.

GLISSANT, E. Le discours antillais. Paris: Seuils, 1981.

GRUZINSKI, S. O pensamento mestiço. São Paulo: Companhia das Letras, 2001.

LEAL, C. Emanoel Araujo: No Brasil, acham que lugar do negro é numa África imaginária. Disponível em http://terramagazine.terra.com.br/interna/0,,OI5510224EI6581,00.html. Acesso em $11 \mathrm{de}$ dez 2011.

NUNES, B. Antropofagia ao alcance de todos. In: ANDRADE, O. de. A utopia antropofágica. São Paulo: Globo, 1995.

PIGNATARI, D. Marco Zero de Andrade. In: Contracomunicação. São Paulo: Perspectiva, 1971.

PRADO, P. Retrato do Brasil. Organização Carlos Augusto Calil. São Paulo: Companhia das Letras, 1997.

REGO, J. L. do. Paulo Prado. In: PRADO, P. Retrato do Brasil. Organização Carlos Augusto Calil. São Paulo: Companhia das Letras, 1997.

SCHWARTZ, J. Vanguardas latino-americanas. São Paulo: EdUsp: Iluminuras: FAPESP, 1995.

SCHWARZ, R. A carroça, o bonde e o poeta modernista. In: Que horas são? Ensaios. São Paulo: Companhia das Letras, 1987.

WHITE, H. Trópicos do discurso: ensaios sobre a crítica da cultura. Tradução Alípio Correia de Franca Neto. 2. ed. São Paulo: Ed. Usp, 2001.

Recebido em: 14 de dezembro de 2011.

Aprovado em: 05 de agosto de 2012. 